\title{
The Shona Subject Relation: Some Selectional Principles
}

\author{
Isaac Mhute \\ Department of Languages and Media, Zimbabwe Open University \\ isaacmhute@gmail.com \\ Maxwell Kadenge \\ Department of Linguistics, University of the Witwatersrand \\ maxwell.kadenge@wits.ac.za
}

Doi:10.5901/mjss.2014.v5n27p1592

\begin{abstract}
This article presents some selection principles of the subject relation in Shona, a southern Bantu language spoken in Zimbabwe. The selectional principles are based on the morphological and semantic characteristics of the preverbal noun phrase (NP). The data for this investigation came from the authors who are native speakers of two main Shona dialects, namely, Zezuru and Karanga. Data was analysed using the projection principle, a branch of government and binding (GB) theory, as well as the seven selectional principles established in well researched languages. It came out that no single selectional rule can cater for all the possible Shona sentences. We demonstrate that seven selectional principles are required for a holistic account of the subject relation in Shona. We also show that there are instances where the selectional rules contradict. As a result, we suggest a hierarchy of reliability to cater for this: namely, thematic or semantic reasons $>P A H$ selection > morphological reasons $>$ topicality in word order > intransitivity assumption > dummy subject. As there are few descriptive and theoretical studies on Shona syntax, this research recommends more studies on this subject.
\end{abstract}

Keywords: grammatical relation; subject relation; Karanga; selectional principles; projection principle

\section{Introduction and a Brief Literature Review}

The article presents selectional principles that can be used to identify the Shona subject relation. Shona is a southern Bantu language spoken by about 10 million Zimbabweans. Although the description and analysis of the subject relation has been a subject of considerable descriptive and theoretical research, little is known about this grammatical relation in Shona. Grammatical relations are understood to be the relationships existing between the head of a predicate and its argument phrases particularly subject and object in a sentence. Cook (1988), Robins (1991) and Tarugarira (1996) argue that it is in fact a presupposition that every existing language has grammatical relations. They claim that conclusions on such aspects of the notion of grammatical relations have been based upon implicational universals. Implicational universals are those universal claims based on evidence from a number of languages and can be discredited at any time in future by the discovery of some negative evidence from one or so languages. They argue that it is because of this background that such aspects have remained in a vague state for so long. They are of the opinion that more researches must be carried out across the languages to make sure conclusions based upon concrete evidence put an end to the ones based upon implicational universals.

Blake (1982:63) is of the opinion that 'the existence of thematic relations is inevitable but grammatical relations are not and one can easily imagine a language without them'. Blake (1982:73) further points that 'direct object is not as firmly established as the frequent use of the term suggests, and subject is certainly not universal.' These observations show that the issue of a subject relation as a universal grammatical relation is questionable.

Kuno (1973), Chomsky (1981) and Panfilov (1994) observe that notions of the syntactic level of language, that is, the grammatical subject and the grammatical predicate are developed within a language as specific forms for expressing the logical categories of that specific language. For example, Kuno (1973) observes that Japanese does not impose most of the restrictions that English places on its grammatical relations. Japanese can accept all possible word orders provided the verb is placed sentence-finally.

However, Mohanan (1988:230) observes that 'relations are a property of the structure of all natural languages of the world and every language exhibits some fundamental processes dependent on them'. Similarly, Bresnan (1982) 
argues that grammatical functions are universal primitives of syntax, not derived from phrase structure representations or from semantic notions. Bresnan rather perceives grammatical functions as lexically encoded in predicate argument structures (PASs) of all languages in varying ways and constituent structure categories are universally decomposed into features. Grammatical functions are syntactically encoded directly in surface representations of phrase structure, according to structuring configurations or morphological features. Mohanan (1988), for example, describes these relations as a universal notion whose different ways of realization are currently acting as the basis for the typological distinction between configurational and non-configurational languages. Everaert, Van Riemsdijk, and Goedemans (2006) support the position above by commenting that in contrastive linguistics the subject was first defined to be the main argument of a proposition and since then, linguistic theories have been developed to describe it in languages all over the world. The notion, however, lacks detailed documentation in Shona, hence the current effort to cover it here.

The subject noun phrase has to be original, preceding the verbal complex and agreeing with it (Hudson, 1984). It thus has to occupy the position that Ouhalla (1994) terms the 'subject position', that is, the position immediately preceding the auxiliary in an active sentence. Brown and Miller (1985) forward a similar account for the type of subject they call the grammatical or morphological subject. The name stems from the fact that it dictates the morphological composition of the predicate failure of which ungrammaticality will result. For instance, noting that all entities controlling agreement and the agreement markers are italicized, the following example must be as follows:

(1) dare ri-a-per-a $\quad \rightarrow \quad$ dare rapera

Cl.5-court session Cl.5 Agr-end-Tv

'the court session has ended'

Example (1) is grammatical because of the concordial agreement between dare 'court session' and ra- 'has' both of which are class 5 . The Shona class 5 agreement marker is (ri-). When it is used together with the past tense marker $\{a\}$ the hiatus between the /i/ of $\{\mathrm{ri}-\}$ and the $/ \mathrm{a} /$ is resolved through the deletion of the first vowel hence the subject marker is reased as \{ra-\} as shown (1) above. However, if it is used together with future tenses that are useful like in rinopera 'it will end' it is realized as [ri-] because there is no vocalic hiatus to resolve. The future tense marker in this case is [no-] 'will'. Violation of concordial agreement results in ungrammatical forms as shown in (2) below:

(2) *dare u-a-per-a. *dare wapera

Cl.5-court session' Cl1.1 Agr-Pst-end-Tv

'the court session has ended'

This ungrammaticality in (2) is a result of the absence of concordial agreement between the class 5 noun dare 'court session' and the class 1 subject marker [wa].

In addition to its special entailment (Ouhalla, 1994), Brown and Miller (1985) specify that this NP's positional location makes it the automatic controller of agreement within the sentence and in most languages it achieves this effect by prefixing its marker onto the verbal complex. For instance, in (1) the class 5 NP dare 'court session' imposes its class 5 agreement marker [ri-] on to the verbal complex thereby ensuring grammaticality. Kuroda (1976) refers to the logical subject as normally playing the surface subject role. Kuroda (1976:110) asserts that '....we may agree to understand by surface subject that constituent of a sentence determining the surface form of the verb, that is, the constituent of a sentence that the main verb agrees with in number and person'.

Wlodarczyk and Wlodarczyk (2008) observe that a subject in English typically matches two types of patterns, namely, agreement and word order. It agrees with the verb group of its clause and is positioned in certain particular ways. Agreement is one of two different forms of the verb (three in the case of the verb 'be') depending on the number and person of its subject. Noonan (1985) makes use of positional terms to describe the subject relation as the topical subject. In this case, the relation is expressed as the occupant of the sentence-initial position, that is, the one referred to by Ouhalla (1994) the subject position. Similarly, Kawasha (2002) observes that in Lunda simple sentences the subject comes before the verb whereas the object is an unmarked post-verbal NP. This is the most pronounced gap in a sentence.

Bliss and Storoshenko (2010) examine the connection between the topical gap and the subject relation in Shona and demonstrate that agreement is subject driven in this language. However, their analysis is limited in that it seems to limit the delineation of the subject relation in Shona topical and morphological terms alone. We build on this observation and suggest semantic criteria for selecting the subject relation. Brown and Miller (1985:69) discuss what they call the 'logical' or 'semantic' subject. They describe it as the 'referent' because it is the entity to which the verbal complex or predicate refers. In the same vein, Allen (1992) describes the subject relation as a noun or its equivalent about which a sentence is predicated and with which the verb agrees. Marantz (1981) is of the view that the term 'logical subject' involves a confusion of distinct levels of representation. Marantz (1981) views the subject relation as the 'thematic argument' of a predicate that has the feature [Subj] assigned to it in the unmarked distinctive lexical form. 
Lee (1974) describes the subject relation in its structural sense as the actor involved in the under transformation of 'actor-action-acted of the kernel sentence'. Hopper and Thompson (1982) characterize it as a prototypically transitive construction. They say 'a prototypically transitive construction is one in which an action is carried over from an agent to a patient and the action must have a direct effect on the patient' (Hopper and Thompson, 1982:67). The agent or the carrier of the action acts as the semantic, thematic or logical subject. The patient becomes the object of the action.

As Kuroda (1976) notes, there are a number of ways through which languages mark their relations. Some languages use word order more than morphological markings, which is the case in English and Japanese respectively while others have no definable word order and use only morphological markings, which is the case with Walpiri and Malayalam (Langacker, 1991). Considering these cross-linguistic variations, it is important to examine the features of grammatical relations in different languages. Cook (1988), Robins (1991) and Tarugarira (1996) concur on the fact that it is a mere presupposition that all languages have grammatical relations. Previous studies show that there is no clear cut definition for the concept subject relation.

\subsection{Selectional principles and the projection principle}

Mohanan (1988) defines selectional principles or rules as the considerations leading to the assignment of syntactic or functional roles onto certain lexical items in sentences. In other words, they specify why certain participants qualify to be labelled as the subjects or objects in their respective sentences. Haegeman (1998), quoting Chomsky's Public Lecture on Government and Binding Theory (GB), comments that the projection principle (PP) is a stipulation proposed by Noam Chomsky's as part of the phrase structure component of generative transformational grammar. Under the PP, the properties of lexical items are preserved while generating the phrase structure of a sentence. For example, the verb 'strangle', apart from the subject, has an obligatory argument, its object. Allen (1992) describes the PP as a principle in GB theory by which the range of elements with which a unit combines is projected from the lexicon as restrictions on syntactic structures that use it. For instance, the ditransitive verb isa 'put', in addition to the external argument (subject), takes an object NP and a locative phrase as an oblique, as demonstrated in (3) below:

(3) [Monica] aisa [bhuku] [patafura].

[Monica] put [the book] [on the table].

Subject Object Oblique

These requirements are specified as part of the information that constitutes its entry in the lexicon. Therefore, by the PP, any syntactic structure in which isa 'put' appears must, at whatever syntactic level, have these elements represented within them. Roberts (1997) claims that all thematic roles associated with all lexical heads present in the structure must be realized by all categories bearing the thematic roles.

Rappaport and Levin (1988) assert that the PP ensures that many aspects of a clause are determined by the syntactic complement taking properties of the predicate that heads it. Palmatier (1972) notes that projection rules produce semantic interpretations of sentences on the basis of their phrase structure, dictionary entries and transformational history. They select the appropriate senses of the lexical items to provide correct readings for each grammatical structure in the final derived phrase marker. They proceed from the bottom of the constituent structure to the top, interpreting the proper reading for each lexical item, amalgamating readings into an amalgam with a grammatical marker until the sentence is associated with a set of readings, that is, its semantic interpretation.

Palmatier (1972) also talks of projection rules of which type 1 rules operate on the final derived phrase marker of kernel sentences, which are sentences produced without any optional transformations. Type 2 rules provide a separate semantic interpretation for sentences constructed using optional transformations, revealing how a derived sentence is related in meaning to its source sentences. There is a single distinct projection rule for each grammatical relation. Palmatier further notes that projection rules are not ordered in respect to each other but apply when their conditions are met.

Similarly, Chomsky (1981) observes that representations at each syntactic level, that is, Logical Form (LF) and deep and surface structures are projected from the lexicon for they observe the syntactic properties of lexical items. The natural intuitive sense of the principle is that every syntactic representation should be a projection of the thematic structure and the properties of lexical entries. Cook (1988) asserts that the principle demonstrates the interface between syntax and morphology, that is, the link between words and the syntactic configurations in which they occur. Bresnan (1982) assumes a similar position by noting that the role of grammatical functions in the lexical-functional theory of syntax is to provide the mapping between surface categorical structure and semantic predicate argument structure. This is achieved by assigning the grammatical functions' semantic roles and syntactic realizations in the categorical component of the syntax. 
Grimshaw (1991) notes that in the lexical-functional theory of syntax, lexical items sub-categorize for function, not constituent structure categories, and lexical items exert their selectional restrictions on a subset of their sub-categorized functions. Bresnan (1982) is of the opinion that though some verb types do not impose selection restrictions on their external arguments others do. For instance, whilst isa selects an animate subject some such as tyisa 'frighten' only select an animate object in Shona. They do not have selectional restrictions associated with the external relation, 'subject'. Generalizations based on theories such as PP must lead to the conclusion that the results of a test are correct or wrong (Chapin 1967).

Roberts (1997) observes that where there are agents they are always the subjects but subjects are not always agents. In other words, it is crucial to ensure that semantic roles have some kind of syntactic realization. This can be achieved by the PP since it can be used to verify the roles played by participants by checking the claims of their lexical items' lexical entries. In this article we are particularly concerned with the thematic structure of the predicates; the number and type of arguments each predicate takes.

Haegeman (1998) points out that the thematic structure associated with lexical items must be saturated in the syntax, as stated in the theta criterion, a part of the PP. The theta criterion states that each argument is assigned one and only one theta role. Furthermore, each role is assigned only to one argument. Roberts (1997) argues that the most vital thing about theta roles is that each role in the entry of a lexical category corresponds to one argument in the syntax.

\section{Entities' Topicality in Word Order}

In this section the data gathered for this study is analysed. We seek to establish the extent to which entities' topicality in word order determines their subjecthood in Shona. In Shona, kernel active sentences are basically of the Subject Verb Object (SVO) order. Like in other Bantu languages, the Shona subject occurs before the verb whereas the object is an unmarked post-verbal noun phrase. In this language, the subject is topical, is followed by the verbal complex and lastly the object. A topic is the most pronounced participant or focus of a sentence. In Shona, it is the occupant of a simple active sentence's initial position as shown in the examples below:

(4) Muchaneta u-a-miny-a piritsi. Muchaneta waminya piritsi

Cl.1a-Muchaneta Cl.1a.Agr.-Pst-swallow -TV Cl.5 'tablet'

minya <Agent Theme>

Muchaneta [+HUMAN, +SINGULAR]

piritsi [-ANIMATE, -ABSTRACT, +SINGULAR]

'Muchaneta swallowed a tablet'

(5) Joana a-fuk-a gumbezi Joana akafuka gumbezi

Cl.1a.-Joan Cl.1a Agr.-Pst- cover-Tv Cl.5.-blanket

fuka <Agent Instrument>

Joana [+HUMAN, +SINGULAR]

gumbezi [-ANIMATE, -ABSTRACT, +SINGULAR]

'Joana covered herself with a blanket'

Muchaneta and Joana in (4) and (5) are subjects and are placed sentence-initially. In other words, they occupy the preverbal position. In Shona, this is the most pronounced gap. This observation gives credence to Hudson's (1984) argument that the subject relation is the referent in a sentence or its pragmatic focus. This is the canonical subject position (Lehman, 1992). Therefore, Shona is a topic-prominent language. According to Hale and Keyser's (2002), in the Topic Theory, which is similar but not equivalent to the Theme Theory of the School of Prague, the subject is also the topic of a proposition in the default word order. According to this theory, in some languages one cannot determine a topic without converting a complement into a subject. As such, ascribing a passive voice to the verb group tropicalizes the complement. The following section presents the morphological and/or grammatical features of the Shona subject.

\section{Agreement}

The occupation of the topical position in active sentences by NPs makes them the automatic controllers of agreement in Shona sentences. Dembetembe (1976) notes that if a noun phrase has its class feature copied on to the auxiliary in the structural change of the gender copying rule, that noun phrase is in a subject position. Stockwell (1977) also describes the agreement rule as a type of constraint on the form of words occurring together, adding that it requires the form of one entity to be altered in order to match that of the one controlling agreement. Wlodarczyk and Wlodarczyk (2006) also observe that in languages like English, subjects govern agreement on the verb or auxiliary verb that carries the main 
tense of the sentence. The examples below exemplify how the Shona subject controls agreement.

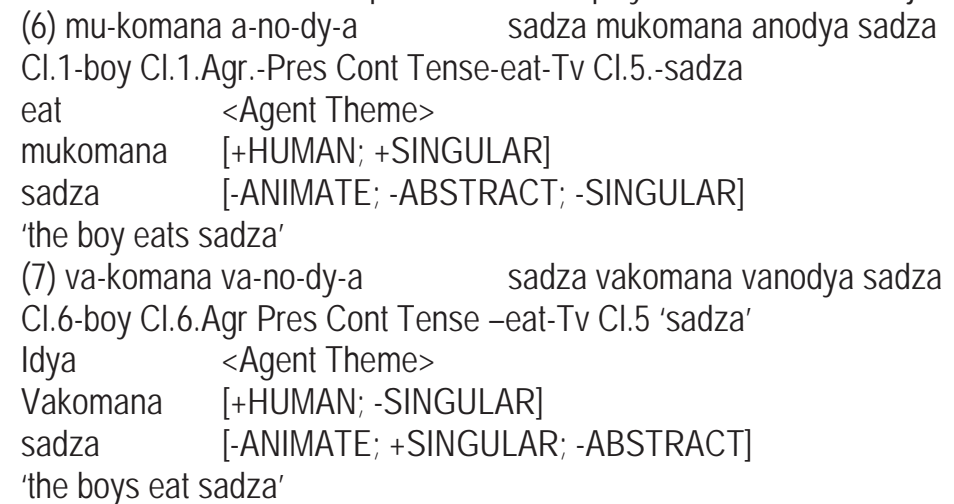

In (6) mukomana 'boy' 'belongs to the Shona noun class 1 and because it occupies the subject position it imposes it its class 1 agreement marker a- on to the verbal complex anodya 'eats'. In example (7) agreement is satisfied because the class 2 noun vakomana 'boys' has imposed its class 2 agreement marker va- onto the verbal complex vanodya 'they eat'. In Shona, like in most Bantu languages, the subject prefix is obligatorily marked on the verb. The forms of the verbal complexes are required to match the class, number and gender of the subject NP. For example, in example (6) above the class 1 noun mukomana 'boy' and the agreement marker a- share the features: number (singular), gender (male) and class 1. Halliday and Matthiessen (2004) observe that the subject has the grammatical function in a sentence of relating its constituent (a noun phrase) by means of the verb to any other elements present in the sentence, that is, objects, complements and adverbials. Consider the following examples too:

(8) va-dzimu va-idu vo-dzoser-a tsika pakare vadzimu vedu vodzosera tsika pakare

Cl.2-ancestor Cl.2.-Poss Cl.2.Agr-restore-Tv Cl.10-traditions Cl.16-original position

dzosera <Agent Patient or Theme Goal>

vadzimu vedu [+HUMAN, +ABSTRACT, -SINGULAR]

tsika dzedu [-ANIMATE, +ABSTRACT, -SINGULAR]

"our ancestors are restoring our norms and values to their original position"

(9) shuro i-a-ba bagwe shuro yaba bagwe

Cl.9-hare Cl.9.Agr-Pst-steal-Tv Cl.5-maize cob

iba <Agent Patient >

shuro [+ANIMATE,-HUMAN, +SINGULAR]

bagwe [-ANIMATE, -ABSTRACT,+SINGULAR]

'The hare stole a maize cob'

In example (8) the subject vadzimu 'ancestors' belongs to class 2 and it is marked by the class 2 subject marker va- in the verbal complex. In addition, it is plural and human. Similarly, in example (9) the subject is the class 9 noun shuro 'hare' and it agrees with the class agreement marker ya- 'has' in the verbal complex yaba 'it has stolen'. It is singular and inhuman. The agreement markers share morphological features with the nouns occupying the topical position.

In sum, in Shona the subject is the topical word which controls sentential agreement. This is has been demonstrated in (8) and (9) in which NPs vadzimu vedu 'our ancestors' and shuro 'hare' occupy the sentence initial gap and control agreement. It is for this reason that the topical subject relation is often described as the morphological or grammatical subject. Wlodarczyk and Wlodarczyk's (2006) show that the subject both agrees with the verb group of its clause and is positioned in certain ways.

\section{Semantic Principles}

According to Hudson (1984), typical subject relations can be termed the semantic or logical subjects of their respective sentences. This is explained by the fact that they have a direct effect on the state of their direct objects since they carry the actions minimally expressed by the verbs onto the direct objects. Similarly, Moro (1997) notes that the concept of subject is either mixed with actors or with carriers of attributes. When this happens, it is defined as the argument that generally refers to the origin of the action or the initiator of the state shown by the predicate. This is the type of relation obtaining between vadzimu vedu 'our ancestors' and tsika traditions' in example (8) above. The former is the only entity within the sentence actively involved in the restoration of the traditions. The same applies to shuro 'hare' in example (9) 
which is the only entity actively involved in stealing the maize cob. It relates to the object in quite a unique way in its sentence. It is for this reason that this grammatical relation is often termed the obligatory or logical subject. In addition, even after the application of transformational rules, the semantic subject is the only NP whose role cannot be played by any other entity within that sentence. However, such a relation seems only obtaining in prototypically transitive sentences. Prototypically transitive sentences are those sentences involving an agent and a patient. They are prototypical because there is a clear cut relationship between the participants as it involves the entities at the two ends of the thematic hierarchy continuum. In intransitives and sentences where there are no such clear-cut relationships, for example, where there is an experiencer and a patient, no entity has a direct effect on the object as shown in (10) below:

(10) mu-komana a-no-d-a sadza mukomana anoda sadza

Cl1.- boy Cl.1Agr- Pres Cont Tense-like-Tv Cl.5-sadza

ida < Experiencer Patient >

mukomana [+HUMAN, +SINGULAR]

sadza [-ANIMATE, -ABSTRACT]

'the boy likes sadza'

In example (10) there is no direct effect - where one participant determines the state of the other- between mukomana 'boy' and sadza 'staple food of Zimbabwe'. The relation is not as clear-cut as it is in (6). The subject mukomana does not determine the state of sadza as is normally done by a typical semantic subject. To account for the assignment of the roles to the participants involved in such cases, we considered the person animacy hierarchy (PAH) as it is presented by Hyman and Duranti (1992).

\subsection{Person animacy hierarchy (PAH)}

The PAH is a ranking of the world's entities to which sentences can refer in the following order:

(11) $1^{\text {st }}$ person singular $>1$ st person plural $>2$ nd person singular $>2$ nd person plural $>3$ rd person singular $>3$ rd person plural $>$ animates $>$ inanimates

All of the entire world's entities to which sentential phrases can refer are included in this ranking. Hyman and Duranti (1992) observe that most Bantu languages observe this principle. According to this selectional rule, the higher an entity ranks on the PAH the greater the chances it has of being accorded the subject status in an active sentence. In other words, if $A$ is a participant that is animate in a sentence it has the first priority to subjecthood before $B$ which is an inanimate participant. This is demonstrated in example (12) below:

(12) Shumba dzi-no-uy-a ku-mu-sha kwa-Nyasha shumba dzinouya kumusha kwaNyasha

Cl.10-lion Cl.10.Agr fut Tense- come-Tv Cl.15-Loc-Cl3.-home-PossCl.1a-Nyasha

uya <Agent Goal>

shumba [+ANIMATE; -SINGULAR]

kumusha kwaNyasha [-ANIMATE; -ABSTRACT; +SINGULAR]

'lions come to Nyasha's home'

In example (12) the animate NP shumba lions' is automatically assigned the subject status for it ranks higher than kumusha kwaNyasha 'Nyasha's home' which is inanimate. The latter is the object of this sentence. Although shumba 'lions' does not determine the state of kumusha kwaNyasha, which is the order necessary when using semantic principles, the two can still be assigned to different syntactic roles using the PAH. There are, however, instances in Shona where a sentences contains arguments belonging to the same class on the PAH as shown in (13) below:

(13) va-tongi va-i-ty-a hama dzi-avo vatongi vaitya hama dzavo

Cl.2.-judges Cl.2.Agr. Hab Tense-fear-Tv Cl.10.-relatives. Cl.10. -there

itya $\quad<$ Experiencer Patient>

vatongi [+HUMAN; -SINGULAR]

hama dzavo [+HUMAN; -SINGULAR]

'Judges feared their relatives.'

In example (12) both vatongi 'judges' and hama dzavo 'their relatives' belong to the class of $3^{\text {rd }}$ person plural but are assigned to different syntactic functions in the sentence. The explanation for this assignment cannot certainly be found in the semantic principles and the PAH. Topicality and morphological features could be used to ascertain the roles of these relations but this is limited because the two usually co-occur. In order to account for this in an insightful manner we invoked the principle of the thematic hierarchy (TH) (Kangira, 2001). The TH ranks thematic relations in a hierarchy as follows: 
(14) Agent $>$ Beneficiary or Benefactor $>$ Maleficiary or Malefactor $>$ Source $>$ Goal

$>$ Experiencer $>$ Instrument $>$ Theme or Patient $>$ Location

The Agent ranks highest and the Location lowest, depending upon the school of thought in use. The ranking is a matter of degree and all the other thematic (theta, semantic) roles are placed in relation to their likeness to the Agent or Location role. The TH takes the Agent and the Location roles as its prototypes. The more the prototypical Agent entailments a participant has, the higher it is ranked on the list. The more prototypical patient entailments a participant also has, the lower it is ranked on the hierarchy. The hierarchy predicts an increase in a function's preference to the subject position from right to left as well as an increase of the preference to object position from left to right. In other words, the Agent and the Location are predicted as the most likely and frequent candidates for the subject and object positions respectively (Siewierska, 1991).

In Shona, as shown in (12), vatongi 'judges' and hama dzavo 'their relatives' are both $3^{\text {rd }}$ person plural. The TH is useful in delineating the roles of these participants. Vatongi 'judges' is an Experiencer and has more prototypical Agent entailments than hama dzavo 'their relatives', which is a mere Patient. Though the two participants belong to the same class on the PAH, they can still be assigned to different syntactic slots based on their rankings on the $\mathrm{TH}$. The $\mathrm{TH}$ considers the semantic relationships between the two arguments in relation to the predicate involved. It is for this reason that the selections made by these two principles always coincide. This explains why the semantic subject is often termed the thematic subject (Brown \& Miller, 1985). It is important to note that the principles presented so far, apart from the topicality and morphological reasons, can only handle situations in which two or more participants are involved. However, in Shona there are cases in which the sentences comprise of solitary participants. To explain the assignment of syntactic roles involved in such situations we draw from Comrie's (1981) intransitivity assumption.

\section{Intransitivity Assumption}

According to the intransitivity assumption, where only one argument is involved, it is automatically accorded the subject status in the sentence. This is a sound assumption for it was modelled alongside the demand of the extended projection principle (EPP) that all sentences should have subjects of some sort (Haegeman, 1998). In addition, Halliday and Matthiessen (2004) note that the subject was first defined to be the main argument of a proposition adding that since then, linguistic theories have been developed to describe languages all over the world with some, such as Systemic Functional Theory, claiming that all clauses must have a subject no matter what language is being described. A good example of one such solitary participant playing the subject role is evident in example (15) following:

(15) danda ri-a-vor-a danda ravora

Cl.5-log Cl.5 Agr-Pst-rot-Tv

vora <Theme>

danda [-ANIMATE; -ABSTRACT; +SINGULAR]

'a log has rotten'

In example (15) danda 'a log' is a Theme, a role which is at the bottom of the TH. It is, however, accorded the subject status because it is a solitary participant. The example below helps us in elucidating the relation between grammatical relations, thematic roles and the $\mathrm{TH}$.

(16) bere ri-a-dy-a John bere radya John

Cl.5-hyena Cl.5Agr-eat-Tv Cl.1a-John

idya $\quad$ Agent Theme>

bere [+ANIMATE; +SINGULAR]

John $\quad$ [+HUMAN; +SINGULAR]

'a hyena ate John'

According to the PAH, in (16), John is supposed to be ranked higher than bere 'hyena' because John is inanimate whilst bere is animate. Contrary to this selection, the TH ranks bere 'hyena' highest for it is directly involved in initiating and carrying out the action specified by the verb to its logical end. It is, therefore, an Agent. We established the following hierarchy of reliability:

(17) TH or Semantic > PAH > morphological $>$ Topicality > Intransitive Subject

\section{Dummy Subject}

In analysing the Shona subject relation it is important to take note of the fact that though it is difficulty to single one selectional rule or principle for the subject relations, the six rules presented above are useful in handling all the possible 
cases of relationships one can find except one. There are situations in our data where no type of subject makes sense as we demonstrate in this section. These are instances where none of the selectional rules discussed so far can account for the selection of the subject involved. These situations involve what we refer to as dummy subjects. These are place holders - though they may be topical in a sentence they do not control agreement. This is shown in example (18) below.
(18) zvi-no-tyis-a ku-gar-a.

Cl.8-it-Fut Tense-frighten-Tv Cl.17.Agr.-stay

tyisa <Source Experiencer>

'it is frightening to stay.'

Example (18) above is a grammatical Shona sentence. Zvi 'it' is the dummy subject. It does not control agreement in the sentence as evidenced by the absence of any other highlighted entity that agrees with it in the sentence. It is just playing a solely grammatical position.

\section{Conclusion}

The article set out to identify and discuss selectional criteria for the Shona subject relation. The selection of the Shona subject relation has been based on a number of principles. First, an entity's topicality in word order, that is, its occupation of the sentence initial position makes it the topical subject in a sentence. Second, a word's ability to control agreement in a sentence makes it the morphological or grammatical subject of that sentence. This effect is achieved in Shona by the placement of morphological markers which agree with the entity in question onto the verbal complex involved. Third, semantic reasons can also be considered in the selection. In this case, entities selected following this principle are termed semantic subjects and are those with a direct effect on the direct object. Such subjects are encoded at the lexical functional level and cannot be amended by any surface structure rule. We also demonstrated that Shona sentences can have solitary arguments called intransitives. In such cases, we used the intransitive assumption which holds that if there is a solitary argument in a sentence it becomes the automatic subject. Principles of topicality and morphology are used to confirm subjecthood in such cases. It has also been shown that Shona makes used of dummy subjects which take the form of bound affixes prefixed onto the verbal complexes.

We have argued that the person animacy hierarchy $(\mathrm{PAH})$ and the thematic hierarchy $(\mathrm{TH})$ are useful in selecting the subject relation. For example, in a sentence with two nouns that belong to the same class of animates, like shumba 'lion' and shuro 'hare', the PAH fails to apply. As a result, the selection can be based on the demands of the TH. There are instances when principles may contradict each other. A sentence like Shumba yaruma munhu 'a lion has bitten a person,' brings the contradictions in the demands of the PAH and the TH to the fore. In this case PAH accords munhu 'person' the subject status whilst the TH selects shumba 'lion'. As a result of such contradictions, we have developed a hierarchy that ranks these selectional principles as shown in (19) below:

(19) Thematic or Semantic reasons > PAH selection > Morphological reasons > Topicality in word order > Intransitivity assumption > Dummy subject

\section{References}

Allen, R.E. 1992. Concise oxford dictionary. Oxford: Oxford University Press.

Blake, J. 1982. Syntax and semantics. New York: Cambridge University Press.

Bliss, H. \& Storoshenko, D.R. 2010. Gramaticization of topic in Shona: in Burling, R. 1992. Patterns of language. San Diego: Harcourt Brace Jovanovich, Publishers.

Bresnan, J. 1982. Control and complentation. Linguistic inquiry. 13: 343-434.

Brown, E.K. \& Miller, J.E. 1985. Syntax: A linguistic introduction to sentence structure. London: Happer Collins Academic.

Chapin, P.G. 1967. On the syntax of word derivation in English. PhD thesis, Massachusetts Institute of Technology (MIT).

Chomsky, N. 1981. Lectures on government and binding theory. Dordrecht: Foris.

Comrie, B. 1981. Language universals and linguistic typology. Chicago: Chicago University Press.

Cook, V. 1988. Parameters syntax. New York: St. Martins Press.

Dembetembe, M.C. 1976. The syntax of sentential complements in Shona. PhD thesis, University of London.

Everaert, M.; van Riemsdijk, H.; Goedemans, R. 2006. The Blackwell companion to syntax, volumes I-V. London: Blackwell.

Grimshaw, J. 1991. Extended projections. New York: MS, Brandeis University.

Haegeman, L. 1998. Introduction to government and binding theory. Oxford: Blackwell Publishers.

Hale, K. L. \& Keyser, S.J. 2002. Prolegomena to a theory of argument structure. Cambridge: Massachusetts.

Halliday, M.A.K. \& Matthiessen, C.M. I.M 2004. An introduction to functional grammar. London: Hodder Arnold.

Hopper, P.J. and Thompson, S.A.1982. Syntax and semantics 15: studies i transitivity. New York: Academic Press.

Hudson, R. A. 1984. Word grammar. Oxford: Blackwell. 
Hyman, L.M. \& Duranti, A. 1992. On the object relation in Bantu, in Syntax and Semantics: Studies in Transitivity edited by P. Hopper \& S.A. Thompson. New York: Academic Press: 218-238.

Kangira, J. 2001. Transitivity in Kalanga. Masters thesis, University of Zimbabwe.

Kawasha, K.B. 2002. Grammatical relations and relativization in Lunda. Journal of African Languages and Linguistics 23(1): 31-62.

Kuno, S. 1973. The structure of the Japanese language. Cambridge, Mass: MIT Press.

Kuroda, S. 1976. The concept of subject in grammar, in Syntax and semantics: Japanese generative grammar edited by M. Shibatani. New York: Academic Press.

Langacker, R.W. 1991. Foundations of cognitive grammar 2: Descriptive application. Stanford: Stanford University Press.

Lee, B.D. 1974. The semantics of Inibalo verbal affixes. Lingua 3:181-218.

Lehman, W. P. 1992. Syntactic typology: Studies in the phenomenology of language. Sussex: The Harvester Press.

Marantz, A.1981. A theory of grammatical relations. Cambridge, Mass: MIT Press.

Mohanan, T. 1988. Cauzativization in Malayalam. California: Stanford University Press.

Moro, A. (1997). The raising of predicates: predicative noun phrases and the theory of clause structure. Cambridge: Cambridge University Press.

Noonan, N. 1985. Complementation, in Language typology and syntactic descriptions: Complex construction II edited by T. Shopen. Cambridge: Cambridge University Press.

Ouhalla, J. 1994. Introducing transformational grammar: From rules to principles and parameters. London: Edward Arnold.

Palmatier, A.R. 1972. A glossary of English transformational grammar. New York: Meredith Corporation

Panfilov, G. 1968. Navaho syntax. Cambridge: The MIT Press.

Rappaport, M. \& Levin, B. 1988. What to do with thematic-roles, in W. Wilkins. syntax and semantics 21. London: Academic Press.

Roberts, I. 1987. The representation of implicit and dethematized subjects. Dodrecht: Foris.

Robins, R.H. 1991. A short history of linguistics. London: Longman.

Siewierska, A. 1991. Functional grammar. London and New York: Routledge.

Stockwell, R. P. 1977. Foundations of syntactic theory. New Jersey: Prentice-Hall Englewood Cliffs.

Tarugarira, J. 1996. Subject relation in Shona. Honours dissertation, University of Zimbabwe.

Williams, E.1988. Argument structure and morphology. Linguistic review 1: 81-114.

Wilkins, W. 1988. Syntax and semantics: vol. 21. London: Academic Press.

Wlodarczyk, A. \& Wlodarczyk, H. 2006. Subject in the meta-informative centering theory. Études Cgnitives / Studia Kognitywne 2006:17.

Wlodarczyk, A. \& Wlodarczyk, H. 2008. Roles, anchors and other things we talk about: associative semantics and meta-informative centering theory. Intercultural pragmatics 5(3):345-365.

\section{Abbreviations used in this article:}

$\begin{array}{ll}\text { Agr } & \text { agreement marker } \\ \text { cl } & \text { noun class } \\ \text { Cont } & \text { continuous } \\ \text { Hab } & \text { habitual tense } \\ \text { Fut } & \text { future tense } \\ \text { Loc } & \text { locative marker } \\ \text { TV } & \text { terminal vowel } \\ \text { LF } & \text { logical form } \\ \text { PP } & \text { projection principle } \\ \text { 1st } & \text { first } \\ \text { SVO } & \text { subject, verb, object } \\ \text { Poss } & \text { possessive formative } \\ 2^{\text {nd }} & \text { second } \\ \text { EPP } & \text { extended projection principle } \\ \text { 3rd } & \text { third } \\ \text { TH } & \text { thematic hierarchy } \\ \text { PAH } & \text { person animacy hierarchy } \\ \text { Poss } & \text { possessive marker } \\ \text { Pres } & \text { Present tense } \\ \text { Pst } & \text { past tense } \\ \text { Subj } & \text { subject }\end{array}$

